University of New Hampshire

University of New Hampshire Scholars' Repository

2001

\title{
A diagnostic study of temperature controls on global terrestrial carbon exchange
}

Tomislava Vukicevic

Colorado State University - Fort Collins

Rob Braswell

University of New Hampshire - Main Campus, rob.braswell@unh.edu

David S. Schimel

NCAR

Follow this and additional works at: https://scholars.unh.edu/earthsci_facpub

\section{Recommended Citation}

37. Vukicevic, T., B.H. Braswell, and D.S. Schimel. A diagnostic study of temperature controls on global terrestrial carbon exchange. Tellus (B), 53:150-170, 2001.

This Article is brought to you for free and open access by the Earth Sciences at University of New Hampshire Scholars' Repository. It has been accepted for inclusion in Earth Sciences Scholarship by an authorized administrator of University of New Hampshire Scholars' Repository. For more information, please contact Scholarly.Communication@unh.edu. 


\title{
A diagnostic study of temperature controls on global terrestrial carbon exchange
}

\author{
By TOMISLAVA VUKIĆEVIĆ ${ }^{1}$, BOBBY H. BRASWELL ${ }^{2}$ and DAVID SCHIMEL ${ }^{3}$, ${ }^{1}$ Cooperative \\ Institute for Research in the Atmosphere, Colorado State University, Ft. Collins, CO 80523-1375, USA; \\ ${ }^{2}$ Max Planck Institute for Biogeochemistry, Postfach 1001 64, Jena, Germany; ${ }^{3}$ National Center for \\ Atmospheric Research, PO Box 3000, Boulder, CO 80307-3000, USA and the Max Planck Institute for \\ Biogeochemistry, Postfach 1001 64, Jena, Germany
}

(Manuscript received 20 July 1999; in final form 15 November 2000)

\begin{abstract}
The observed interannual variability of atmospheric $\mathrm{CO}_{2}$ reflects short-term variability in sources and sinks of $\mathrm{CO}_{2}$. Analyses using ${ }^{13} \mathrm{CO}_{2}$ and $\mathrm{O}_{2}$ suggest that much of the observed interannual variability is due to changes in terrestrial $\mathrm{CO}_{2}$ exchange. First principles, empirical correlations and process models suggest a link between climate variation and net ecosystem exchange, but the scaling of ecological process studies to the globe is notoriously difficult. We sought to identify a component of global $\mathrm{CO}_{2}$ exchange that varied coherently with land temperature anomalies using an inverse modeling approach. We developed a family of simplified spatially aggregated ecosystem models (designated $\mathrm{K}$-model versions) consisting of five compartments: atmospheric $\mathrm{CO}_{2}$, live vegetation, litter, and two soil pools that differ in turnover times. The pools represent cumulative differences from mean $\mathrm{C}$ storage due to temperature variability and can thus have positive or negative values. Uptake and respiration of $\mathrm{CO}_{2}$ are assumed to be linearly dependent on temperature. One model version includes a simple representation of the nitrogen cycle in which changes in the litter and soil carbon pools result in stoichiometric release of plant-available nitrogen, the other omits the nitrogen feedback. The model parameters were estimated by inversion of the model against global temperature and $\mathrm{CO}_{2}$ anomaly data using the variational method. We found that the temperature sensitivity of carbon uptake (NPP) was less than that of respiration in all model versions. Analyses of model and data also showed that temperature anomalies trigger ecosystem changes on multiple, lagged time-scales. Other recent studies have suggested a more active land biosphere at Northern latitudes in response to warming and longer growing seasons. Our results indicate that warming should increase NPP, consistent with this theory, but that respiration should increase more than NPP, leading to decreased or negative NEP. A warming trend could, therefore increase NEP if the indirect feedbacks through nutrients were larger than the direct effects of temperature on NPP and respiration, a conjecture which can be tested experimentally. The fraction of the growth rate not predicted by the K-model represents model and data errors, and variability in anthropogenic release, ocean uptake, and other processes not explicitly represented in the model. These large positive and negative residuals from the K-model may be associated with the Southern Oscillation Index.
\end{abstract}

\section{Introduction}

The growth rate of carbon dioxide in the atmosphere exhibits variations on a range of time

\footnotetext{
* Corresponding author.

e-mail: tomi@cira.colostate.edu
}

scales. Some of the variation is clearly explained by changes in humanity's fossil fuel economy, but other changes result from variability in ecosystem and ocean exchange. The substantial slow-down in the growth rate of $\mathrm{CO}_{2}$ following the eruption of Mt. Pinatubo, with ensuing climatic consequences, provided strong evidence for climate 
forcing of interannual changes in $\mathrm{CO}_{2}$ (Schimel et al., 1995). There have been a number of analyses of the spatio-temporal variations in atmospheric $\mathrm{CO}_{2}$ using inverse modeling from concentrations (Tans et al., 1990; Enting and Mansbridge 1991), changes in the seasonal cycle (Randerson et al., 1997; Myneni et al., 1997) or the trend and interannual variability of the growth rate (Keeling et al., 1995; Braswell et al., 1997). These analyses reveal that there is impact of the processes governing $\mathrm{CO}_{2}$ exchange over land and oceans in the record of atmospheric $\mathrm{CO}_{2}$, its isotopes and oxygen.

The development of networks for ${ }^{13} \mathrm{C}$ and $\mathrm{O}_{2}$ measurements and advances in terrestrial modeling are expanding the utility of the observational record for testing hypotheses about the location and cause of variations in carbon exchange (Keeling et al., 1995; Schimel et al., 1996; Braswell et al., 1997; Rayner et al., 1999). For example, the effects of the Pinatubo eruption (1992) can be rather directly partitioned between land and ocean processes using ${ }^{13} \mathrm{C}$ in $\mathrm{CO}_{2}$ and $\mathrm{O}_{2}$ (Ciais et al., 1995; Keeling et al., 1995). Analyses using ${ }^{13} \mathrm{C}$ and $\mathrm{O}_{2}$ suggest increased terrestrial uptake of $\mathrm{CO}_{2}$ played a large role in the slowdown of the growth rate after Pinatubo (Ciais et al., 1995; Rayner et al., 1999), as do modeling studies of the biosphere (Schimel et al., 1996). The slow down actually began slightly before Pinatubo, provoking us initially to begin looking for complex responses of $\mathrm{CO}_{2}$ to temperature (Schimel et al., 1996). Braswell et al. (1997) used a statistical model to relate temperature anomalies (defined as deviations from the long-term mean) over land to global variations in the growth rate of $\mathrm{CO}_{2}$ and satellite data. Braswell et al. (1997) found significant responses on immediate and lagged timescales, and identified patterns in global terrestrial satellite observations supporting the hypothesis of responses on multiple times-scales.

While correlations between spatio-temporal patterns of climate and of $\mathrm{CO}_{2}$ can be identified, in general there is not sufficient information to unambiguously identify mechanisms. However, there is often sufficient information to exclude certain hypotheses. For example, Randerson et al. (1997) showed that the increase in the amplitude of the $\mathrm{CO}_{2}$ seasonal cycle is inconsistent with $\mathrm{CO}_{2}$ fertilization of photosynthesis as the sole cause of changing NPP. Ciais et al. (1995) showed that the change in $\mathrm{CO}_{2}$ uptake could not be explained by an oceanic mechanism. The Braswell et al. (1997) result suggests that terrestrial $\mathrm{CO}_{2}$ exchange cannot be predicted entirely from an instantaneous relationship with temperature but that longerterm ecological processes must also be at work, consistent with a hypothesis derived from experiments with the Century ecosystem model (Schimel et al., 1996).

In this paper we follow up on the hypothesis that the terrestrial biosphere responds to temperature variability (Fig. 1) on multiple time scales. The Braswell et al. (1997) paper showed positive correlations of temperature on sub-annual time scales (warm years release $\mathrm{CO}_{2}$ to the atmosphere) and negative correlations from a year to $2-3$ years (implying larger-than-usual uptake of $\mathrm{CO}_{2}$ after warm years). Experiments using the Century model suggest a mechanism consistent with the hypothesis. In warm years, respiration of soil organic matter exceeds increases in photosynthesis, leading to a loss of carbon and a release of nitrogen. The effect of this enhanced $\mathrm{N}$ availability may persist for several years (Schimel 1995), leading to increased NPP lasting longer than the temperature direct effect. Statistical analysis of global data can provide relatively little insight as to mechanism beyond that explored in the Braswell et al. (1997) paper. Experiments with ecosystem models can provide additional ideas and hypotheses, but lagged effects which are small locally but significant globally are difficult to test with site-specific data (Goulden et al., 1996).

Most ecosystem modeling involves forward modeling, where ecosystem models are integrated using observed environmental data and then compared to $\mathrm{CO}_{2}$ concentration or flux data. In contrast, most inverse models estimate spatialtemporal distributions of fluxes and do not analyze the relationships between controls over and responses of ecosystems. Our approach of inverting a simple ecosystem model is complementary to both forward ecosystem and inverse geophysical models.

We ask the question "is the observed relationship between temperature and $\mathrm{CO}_{2}$ flux anomalies consistent with our knowledge of biotic responses to temperature". Our understanding of temperature effects on ecosystems is based on studies of "microscopic" phenomena (relative to atmospheric $\mathrm{CO}_{2}$ changes). Can the parameters of a simple 


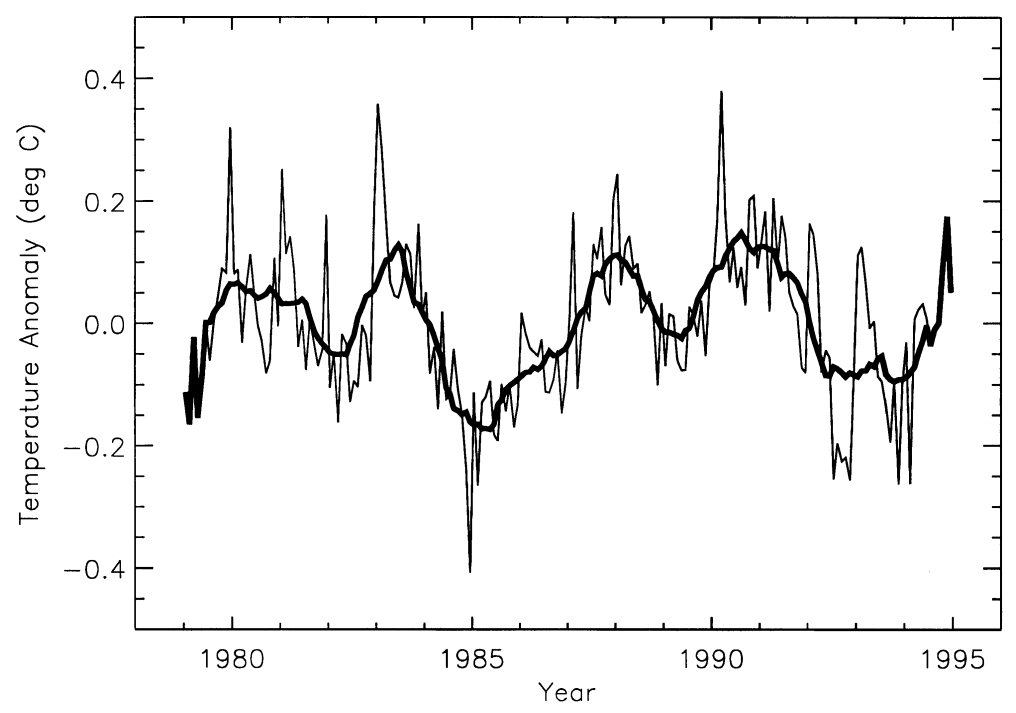

Fig. 1. Global temperature anomaly for 1979-1994 based on compiled weather station data (Jones, 1994; Parker et al., 1994). The thin curve shows monthly anomaly, or departure from the long term mean for that month. A slight trend was removed for the analysis amounting to approximately $0.1^{\circ}$ over the entire period. The thick curve shows these anomalies after 6-month filter was applied.

process model be estimated from "macroscopic" data (temperature and atmospheric $\mathrm{CO}_{2}$ )?

We developed a diagnostic model, based on current global ecosystem models (Parton et al., 1987; Schimel et al., 1997), designed to explain observations of interannual temperature and $\mathrm{CO}_{2}$. The model is simplified and aggregates spatially all ecosystems. The model contains a subset of the global ecosystem model compartments, representing those pools that affect monthly-to-decadal dynamics. We have developed versions with and without a reduced nitrogen cycle. The residual from the fit of the model to $\mathrm{CO}_{2}$ data then contains information on ocean, land use and fossil fuel flux anomalies. This model allows us to explore the consistency of observed temperature and $\mathrm{CO}_{2}$ variations with hypotheses about the large-scale response of ecosystems to temperature from experiments and process models (Holland et al., 1995; Cao and Woodward 1998; Tian et al., 1998). We apply the model to the period 1979-1994.

\section{Methods}

The key components in our analysis are: (1) aggregated global model, (2) global data sets of surface temperature anomalies and $\mathrm{CO}_{2}$ concentrations, (3) model parameter optimization with respect to an observationally based estimate of $\mathrm{dCO}_{2} / \mathrm{d} t$ and (4) evaluation of temperature "transfer functions".

\subsection{K-model}

We constructed a highly aggregated, global model with parameters based on the Century terrestrial biogeochemical model (Parton et al., 1993; Schimel et al., 1996). It is a perturbation model, assuming that responses to anomalous forcing may be superposed upon a steady state system. In this framework, anomalous temperature initially leads to anomalous production and respiration that is "instantaneous" (time scales less than one month) but these changes propagate through the model via vegetation and soil organic matter turnover to potentially yield responses at multiple time scales. We developed a model version with the potential for nutrient feedbacks, as well as a purely biophysical version. The model (which we call the $\mathrm{K}$-model, where $\mathrm{K}$ denotes turnover time coefficients) is a set of five coupled linear differential equations.

The state of the model is represented by five 


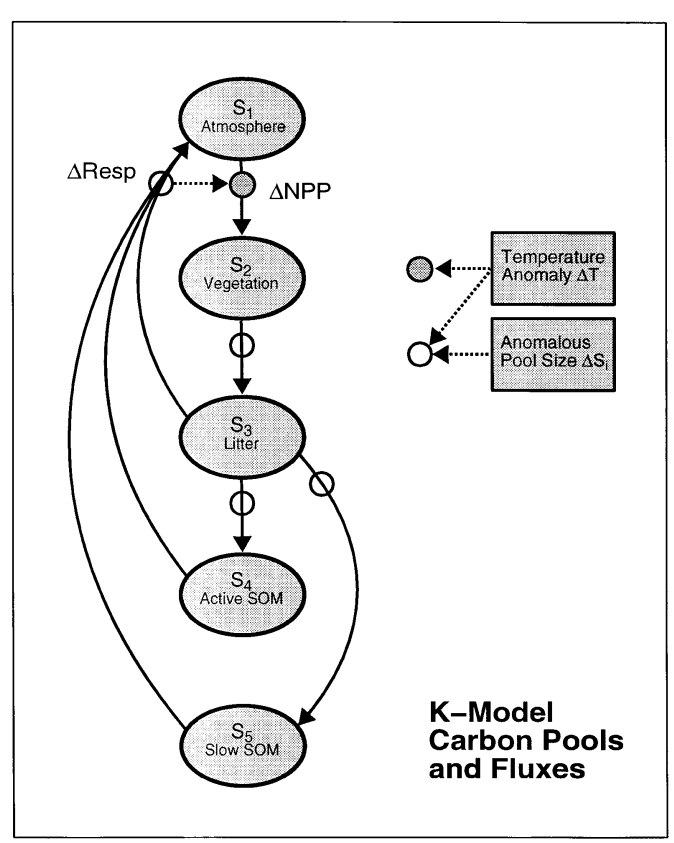

Fig. 2. Schematic showing the pools $\left(S_{i}\right)$ and fluxes of the K-model. Respiration fluxes and exchanges between vegetation and soil/litter pools are controlled both directly by temperature variability and by changes in the pool size (open circles; eq. (6)). Changes in NPP are assumed to be affected by temperature (filled circle), and optionally in the standard case, by a nutrient-related feedback (eqs. (4) and (5)).

pools representing anomalous amounts of carbon in (1) the atmosphere, (2) terrestrial vegetation, (3) litter and detritus, (4) active soil organic matter, and (5) slow and passive soil organic matter (Fig. 2). Because the model simulates temperaturecaused perturbations to an assumed steady state, the amount of carbon at time $t$ in any of these pools represents the amount of excess carbon (which can be negative) due to cumulative effects of temperature variability. The rate of change of carbon in the atmosphere, pool \#1, we assume is commensurate with observations of atmospheric $\mathrm{CO}_{2}$ growth rate. The rate of change of the atmospheric pool is calculated instantaneously as the difference between anomalous plant production and anomalous respiration (henceforth we shall omit the term "anomalous"), and represented simply by

$\frac{\mathrm{d} S_{1}}{\mathrm{~d} t}=\mathscr{R}-\mathscr{P}$, where respiration $\mathscr{R}$ depends directly and linearly upon temperature anomaly $(T)$ with coefficient $\mathscr{Q}_{r}$, and with other terms corresponding to turnover of excess organic matter with specified rates given for each pool:

$\mathscr{R}=\mathscr{Q}_{r} T+k_{3} \mathscr{D} S_{3}+k_{4} S_{4}+k_{5} S_{5}$.

The latter three terms represent indirect consequences of temperature anomalies. The $\mathscr{D}$ coefficient is the fraction of carbon in the plant detrital pool that is respired versus transformed into soil organic matter. The turnover rates themselves $\left(k_{3}, k_{4}\right.$ and $\left.k_{5}\right)$ are also potentially modified by temperature:

$k_{i}=k c_{i}\left(1.0+\phi_{i} T\right)$,

where $\phi_{i}$ represents the fractional change in turnover rate given the temperature anomaly $T$ in Kelvin and $k c_{i}$ are constant turnover rates. Thus, we have allowed for a temperature perturbation to directly yield a respiration anomaly, and to alter the processing rate of the quantity of carbon (positive or negative) which had previously been accumulated in longer turnover time fractions. Production $\mathscr{P}$ is given by the sum of a linear temperature response $\mathscr{Q}_{p}$, and a nutrient feedback term,

$\mathscr{P}=\mathscr{Q}_{p} T+c n_{2} \beta \mathscr{F}$,

where $\mathrm{Cn}_{2}$ is the carbon-to-nutrient ratio of the "new" plant material and $\mathscr{F}$ is a parameter that indicates the strength of the feedback, or nutrient limitation. In dealing with the selection of parameter constraints of this model, we assume that nitrogen is the limiting nutrient, and select values from the literature accordingly. Nutrient availability for plant uptake is simulated in one of two ways: either it is equal to the amount of $N$ mineralized in month $t$ (no time lag), or it is a Gaussian-weighted sum of nutrient mineralization over the past $2 \times n$ months, with maximum weighting at $n$ months, where $n=$ 18 or 24 . Evidence for this mechanism is discussed in Subsection 3.3. Finally, the nutrient mineralization rate is given by mass balance and stoichiometric considerations as

$$
\begin{aligned}
\beta= & \frac{k_{3} S_{3}}{c n_{3}}+\frac{k_{4} S_{4}}{c n_{4}}+\frac{k_{5} S_{5}}{c n_{5}}-\frac{k_{3} f_{34} S_{3}}{c n_{4}} \\
& -\frac{k_{4} f_{35} S_{3}}{c n_{5}}+\frac{\mathscr{Q}_{r} T}{c n_{4}},
\end{aligned}
$$

where $f_{34}$ and $f_{35}$ represent the fractional allocation of soil carbon from litter to either the active 
or slow pools (Fig. 2). Having defined all the relevant parameters and variables, the remaining model state equations for vegetation and soil components simply transform the anomalous carbon (though at variable rates) according to first order coupling coefficients:

$\frac{\mathrm{d} S_{2}}{\mathrm{~d} t}=\mathscr{P}-k_{2} S_{2}$,

$\frac{\mathrm{d} S_{3}}{\mathrm{~d} t}=k_{2} S_{2}-k_{3} S_{3}$,

$\frac{\mathrm{d} S_{4}}{\mathrm{~d} t}=k_{3} t_{34} S_{3}-k_{4} S_{4} \mathscr{Q}_{r} T$,

$\frac{\mathrm{d} S_{5}}{\mathrm{~d} t}=k_{3} t_{35} S_{3}-k_{5} S_{5}$.
From eqs. (1)-(6) (which completely describe the model) we can see that there are 16 parameters (Table 1), the selection of which yields a unique realization (time series output) of the model. The initial values of $S_{1}, S_{2}, S_{3}, S_{4}$ and $S_{5}$ are set to zero. The parameters are given in Table 1, which also includes intervals of acceptable values used in our analyses, and retrieved values, determined via the optimization procedure described in Subsection 2.3.

\subsection{Global data sets}

Our simple globally-parameterized model estimates variations in the terrestrial net flux of carbon (net ecosystem production) that are due to anomalies in global temperature. Therefore, the

Table 1. K-model parameters

\begin{tabular}{|c|c|c|c|c|c|}
\hline Name & Description & $\begin{array}{l}\text { Retrieved } \\
N \text {-cycle }\end{array}$ & $\begin{array}{l}\text { Retrieved } \\
\text { no- } N \text {-cycle }\end{array}$ & $\begin{array}{c}\text { Interval of } \\
\text { acceptable values }\end{array}$ & Units \\
\hline \multirow[t]{2}{*}{$k_{2}$} & vegetation & & & & \\
\hline & $\begin{array}{c}\text { turnover rate } \\
\text { litter }\end{array}$ & 0.17 & 0.11 & $0.04-0.17$ & month $^{-1}$ \\
\hline$k_{3}$ & turnover rate & 0.042 & 0.0083 & $0.0083-0.042$ & month $^{-1}$ \\
\hline$k_{4}$ & $\begin{array}{l}\text { active SOM } \\
\text { turnover rate } \\
\text { passive SOM }\end{array}$ & 0.014 & 0.031 & $0.014-0.042$ & month $^{-1}$ \\
\hline$k_{5}$ & turnover rate & 0.00083 & 0.0042 & $0.00083-0.0042$ & month $^{-1}$ \\
\hline $\mathrm{Cn}_{2}$ & $\mathrm{C}: \mathrm{N}$ vegetation & 66.3 & N/A & $25.0-75.0$ & $\mathrm{gg}^{-1}$ \\
\hline $\mathrm{Cn}_{3}$ & $\mathrm{C}: \mathrm{n}$ litter & 50.0 & $\mathrm{~N} / \mathrm{A}$ & $50.0-150.0$ & $\mathrm{gg}^{-1}$ \\
\hline $\mathrm{Cn}_{4}$ & $\mathrm{C}: \mathrm{N}$ active $\mathrm{SOM}$ & 37.5 & N/A & $12.5-37.5$ & $\mathrm{gg}^{-1}$ \\
\hline $\begin{array}{l}\mathrm{Cn}_{5} \\
\phi_{3}\end{array}$ & $\begin{array}{c}\mathrm{C}: \mathrm{N} \text { passive } \mathrm{SOM} \\
\text { slope of } k_{3}\end{array}$ & 22.5 & $\mathrm{~N} / \mathrm{A}$ & $7.5-22.5$ & $\mathrm{gg}^{-1}$ \\
\hline$\phi_{3}$ & $\begin{array}{l}\text { versus temperature } \\
\text { slope of } k_{4}\end{array}$ & 1.0 & 1.0 & $0.001-1.00$ & month $^{-1} \mathrm{deg}^{-1}$ \\
\hline$\phi_{4}$ & versus temperature & 1.0 & 1.0 & $0.001-1.00$ & month $^{-1} \mathrm{deg}^{-1}$ \\
\hline$\phi_{5}$ & $\begin{array}{l}\text { slope of } k_{5} \\
\text { versus temperature } \\
\text { slope of NPP }\end{array}$ & 0.43 & 1.0 & $0.001-1.00$ & month $^{-1} \operatorname{deg}^{-1}$ \\
\hline $\mathscr{Q}_{p}$ & $\begin{array}{l}\text { versus temperature } \\
\text { slope of resp. }\end{array}$ & 1.66 & 1.22 & $0.001-2.00$ & $\mathrm{gm}^{-2}$ year $^{-1} \mathrm{deg}^{-1}$ \\
\hline $\mathscr{Q}_{r}$ & $\begin{array}{l}\text { versus temperature } \\
\text { strength of }\end{array}$ & 2.00 & 1.60 & $0.001-2.00$ & $\mathrm{gm}^{-2}$ year $^{-1} \mathrm{deg}^{-1}$ \\
\hline $\mathscr{F}$ & $\begin{array}{l}N \text {-feedback } \\
\text { resp. fraction }\end{array}$ & 0.59 & $\mathrm{~N} / \mathrm{A}$ & $0.001-1.00$ & dimensionless \\
\hline $\mathscr{D}$ & of decomposition & 0.45 & 0.49 & $0.20-0.80$ & dimensionless \\
\hline$\beta$ & $\begin{array}{l}\text { slow versus passive } \\
\text { partitioning }\end{array}$ & 0.80 & 0.54 & $0.20-0.80$ & dimensionless \\
\hline
\end{tabular}

Retrieved parameter values using the K-model version with the $N$-cycle included are listed in the column labeled "retrieved $N$-cycle". The retrieved parameter values using the K-model version without the $N$ cycle included are listed in the column labeled "retrieved no- $N$-cycle. The interval of acceptable values for parameters are listed in the column labeled "interval of acceptable values". 
model requires global temperature anomaly time series as input, and produces global anomaly $\mathrm{CO}_{2}$ time rate of change as output $\left(\mathrm{d} S_{1} / \mathrm{d} t\right)$. Simulated $\mathrm{CO}_{2}$ changes are compared to an observationally based estimate of $\mathrm{dCO}_{2} / \mathrm{d} t$.

We used monthly $\mathrm{CO}_{2}$ concentration data from the Climate Monitoring and Diagnostics Laboratory. Observations made using an infrared continuous analyzer system are available for Mauna Loa (MLO) and the South Pole (SPO) from 1979-1994 (Gillette et al., 1987; Thoning et al., 1989). Monthly averages of the continuous analyzer data were used to construct hemispheric $\mathrm{CO}_{2}$ growth rate anomalies, assuming MLO is representative of the northern hemisphere, and that SPO is representative of the southern hemisphere.

We produced $\mathrm{CO}_{2}$ growth rate anomalies from the concentration data in three steps. First, we took the first-differences of the time series yielding a concentration rate of change per month ( $\mathrm{ppm} / \mathrm{mo}$ ). Second, we removed the seasonal cycle by subtracting the monthly mean values calculated for the entire period 1979-1994, yielding a monthly growth rate anomaly. Finally, because of finite atmospheric mixing rates one cannot interpret the rate of change of $\mathrm{CO}_{2}$ observed at the sites as being instantaneously equal to the rate of change of carbon in the atmosphere produced by the surface source anomalies. Therefore, we applied a forward-smoothing filter to remove variations on time scales less than intra-hemispheric mixing time. We used forward smoothing, assuming that the effect of fluxes on carbon in the atmosphere at time $t$ will be reflected in the $\mathrm{CO}_{2}$ observations, because of transport, until some time between $t$ and $t+6$ months.

We used temperature anomalies from land observations to drive the model (Jones, 1994; Parker et al., 1994). These data are provided as monthly anomalies, so no additional processing was necessary to transform this data into the appropriate variable as with the $\mathrm{CO}_{2}$ observations. However, we removed a small positive trend in these data which violates stationarity and could interfere with the primary purpose of our model exercise, which is to study interannual variability. This small adjustment was made using a linear regression with time as the independent variable. The detrended temperature time series is shown in Fig. 1.

\subsection{Optimization of model parameters}

The K-model is designed to represent global responses to globally averaged temperature anomalies. This design makes it is difficult to obtain unique values for the model parameters from direct prior observational or modeling ecosystemspecific estimates. To evaluate parameters for the global aggregate model we made use of the global observations of $\mathrm{CO}_{2}$ and performed the objective parameter estimation using the variational technique. Specifically, a measure of discrepancy between the model solution and observationally based global record of $\mathrm{dCO}_{2} / \mathrm{d} t$ (Subsection 2.2) was minimized via adjustment of the model parameters in Table 1 . The variational parameter estimation technique is well known and has been used in atmospheric and ocean studies to improve model parameter values using observations (Zou et al., 1992; Bennett and McIntosh, 1982; Smedstad and O'Brien, 1991).

The variational parameter estimation method consists of computing parameter values which minimize a cost function. This function is a quadratic measure of model discrepancy with respect to data, written in the current application as:

$$
\begin{aligned}
J= & \frac{1}{2} \int_{0}^{\tau} w_{\mathrm{CO}_{2}}\left[\left(\frac{\mathrm{d} S_{1}}{\mathrm{~d} t}\right)-\left(\frac{\mathrm{dCO}}{\mathrm{d} t}\right)\right]^{2} \mathrm{~d} t \\
& +\frac{1}{2} \sum_{i=1}^{i=16} w_{\alpha}^{i}\left(\alpha_{i}^{\text {optimal }}-\alpha_{i}^{\text {guess }}\right)^{2},
\end{aligned}
$$

where $t$ is time in the interval $(0, \tau=15$ years), $\left(\mathrm{dCO}_{2} / \mathrm{d} t\right)$ and $\left(\mathrm{d} S_{1} / \mathrm{d} t\right)$ are observed and modeled $\mathrm{CO}_{2}$ time rate of change, respectively and $\alpha_{i}^{\text {optimal }}$ and $\alpha_{i}^{\text {guess }}$ are optimal and first guess values of the parameters in Table 1 and $i$ is the parameter index. The coefficients $w_{\mathrm{CO}_{2}}$ and $w_{\alpha}^{i}$ are necessary weights to render the terms unitless and to assign a measure of uncertainty (error) associated with the data and prior values of the parameters, respectively.

It is standard procedure in the variational approach to seek the minimum of the cost function using the Lagrange functional (Daley, 1991). First, an augmented cost function $F$ is defined

$F=J+\int_{0}^{\tau} \lambda(t)\left[\frac{\mathrm{d} S}{\mathrm{~d} t}-\mathscr{K}(S, \alpha)\right] \mathrm{d} t$,

where the term within square brackets is in this study the entire $\mathrm{K}$-model system of equations 
(Subsection 2.1) but expressed in matrix form with $S$ representing the vector of K-model pools, $\alpha$ is the vector of parameters and $\mathscr{K}$ is the nonlinear $\mathrm{K}$-model operator represented with the right hand side (rhs) of eqs. (1) and (6). Because the second term in the rhs of (8) is equal to zero, by definition $F=J$. The new variable $\lambda$ is the Lagrange multiplier. This multiplier is a vector of dimension equal to the number of pools in the model (the dimension of $S$ vector). The utility of $\lambda$ is seen by setting the first order variation of $F$ with respect to the vectors $S$ and $\alpha$ to zero and then integrating by parts. This derivation yields

$\frac{\mathrm{d} \lambda(t)}{\mathrm{d} t}=-K_{\mathrm{S}}^{*} \lambda+w_{\mathrm{CO}_{2}}\left[\left(\frac{\mathrm{d} S_{1}}{\mathrm{~d} t}\right)-\left(\frac{\mathrm{dCO}}{\mathrm{d} t}\right)\right]$,

$\alpha^{\text {optimal }}=\alpha^{\text {quess }}+\frac{1}{w_{\alpha}} \int_{0}^{\tau} \lambda(t) K_{\alpha} \Delta \alpha \mathrm{d} t$

The matrix operators $K_{\mathrm{S}}^{*}$ and $K_{\alpha}$ consist of the first derivatives of the rhs of K-model equations with respect to the state vector $(S)$ and the parameters $(\alpha)$, respectively. Asterisk denotes the adjoint. The matrix $K_{\mathrm{S}}$ is, therefore, the Jacobian of the $\mathrm{K}$-model and the associated adjoint is simply the transposition of this matrix. In (9b), $\Delta \alpha$ is the parameter perturbation vector to be determined from an optimization algorithm. The expression (9a) represents the adjoint system of equations. The expressions (1)-(9) together represent the optimization system for the cost function (7). Because this system is nonlinear it is necessarily solved using iterative optimization algorithms where the first guess parameter values are refined within each iteration using the adjoint system solution.

In this study, the variances and the associated error estimates for the first guess parameters were not known, nor did we have a strong a priori basis for choosing the first guess. We could, however, specify a data based interval of acceptable values for each parameter (Table 1). These intervals were derived from the global range of the corresponding parameters used in the global Century ecosystem model experiments (Schimel et al., 1996). Because the intervals of acceptable values are known, and prior estimates are not available, it was reasonable to assume that the first guess values are all equally uncertain and that their associated variance is large. This assumption renders $w_{\alpha}^{i} \sim 0$. As a consequence we have solved the optimization system (1)-(9) as a constrained minimization (omitting the second term on rhs of (7)) instead of as a Bayesian estimation problem (Tarantola, 1987). Eq. (9b) was replaced with

$\alpha_{n}^{\text {optimal }}=\alpha_{n-1}^{\text {optimal }}+\mathscr{H}\left(\lambda_{n-1}\right)$,

where $n$ is iteration number and $\mathscr{H}\left(\lambda_{n-1}\right)$ is a correction which depends on the adjoint solution. The specific form of the correction term depends on the minimization algorithm. In this study we applied the Quasi-Newton method using a Numerical Algorithms Group (NAG) library routine (E04KDF). Because the optimization problem is nonlinear we also tested the sensitivity of results to variations in the first guess. We started the optimization integrations from the first guess values either using the parameter values equal to the mid-point in the intervals of acceptable values or to a rough estimate of the optimal values obtained via forward model integrations. To obtain the rough optimal first guess we applied Powell's method (Press et al., 1992). The parameter optimization experiments were performed for both the K-model with the lagged $N$-feedback mechanism (standard K-model) and without this feedback (no- $N$ cycle K-mode). There were a total of four optimization experiments which are listed in Table 2.

The weighting coefficients $w_{\mathrm{CO}_{2}}$ were defined as inverse of the error variances for $\mathrm{dCO}_{2} / \mathrm{d} t$. We estimated the error variance by setting it equal to the anomaly variance for the period. Including any other knowledge would reduce the variance. This assumption was used because we wished to avoid over-fitting the data which contains variance due to the fossil and land use sources and due to the ocean and terrestrial ecosystem fluxes. The $\mathrm{K}$-model includes only the terrestrial mechanisms. Thus, the model errors were formally included in

Table 2. Parameter optimization experiments for $N$ cycle and no- $N$ cycle model versions

\begin{tabular}{lcc}
\hline Experiment & Model & First guess \\
\hline NLAG-M & $N$-feedback & mid point \\
NLAG-O & $N$-feedback & rough optimal \\
NONF-M & no- $N$ feedback & mid point \\
NONF-O & no- $N$ feedback & rough optimal \\
\hline
\end{tabular}

Tellus 53B (2001), 2 
the optimization problem through representativeness errors (Tarantola, 1987, chapter 1).

In summary, the model optimization with respect to the observationally based estimate of $\mathrm{dCO}_{2} / \mathrm{d} t$ was performed as constrained minimization assuming significant total error consisting of the prior information error (the first guess error) and the data error (model and observation errors). The results of such optimization can be used to falsify rather than to verify the hypothesis embedded in the model formulation because wide range of retrieved parameter values can fall within the error margins. We have developed model versions with and without a nitrogen cycle (Fig. 3). The optimization experiments were used to test these hypotheses. The overall model evaluation in this study was not based solely on the differences in goodness of fit between different model versions but on several diagnostics, including the formal diagnostics from the inversion and the qualitative comparison of the parameters, temperature transfer functions and cross-correlations.

\subsection{Temperature transfer function}

Similar to the derivation of the parameter optimization system in Subsection 2.3, the variational technique can be applied to derive a functional relationship between the K-model solution or a function of this solution and the temperature variations.

In this application of the variational technique the quantity of interest is a linear diagnostic function $\mathrm{d} S_{1} / \mathrm{d} t$ instead of the quadratic cost function (7). We were interested in lagged responses of $\mathrm{CO}_{2} / \mathrm{d} t$, thus we chose this linear function to be a short time average:

$R\left(\tau_{1}, \tau_{2}\right)=\frac{1}{\left(\tau_{2}-\tau_{1}\right)} \int_{\tau_{1}}^{\tau_{2}} \frac{\mathrm{d} S_{1}}{\mathrm{~d} t} \mathrm{~d} t$

where $\tau_{1}$ and $\tau_{2}$ are the beginning and final times used for the average. We used 3 months as the averaging period. Note that $\mathrm{d} S_{1} / \mathrm{d} t=\mathrm{dCO}_{2} / \mathrm{d} t$ in the model.

The change of $R$ as a function of an arbitrary temperature variation $T^{\prime}\left(t=t^{*}\right)$ is

$\Delta R\left(\tau_{1}, \tau_{2}, t^{*}\right)=\frac{\partial R\left(\tau_{1}, \tau_{2}\right)}{\partial T\left(t^{*}\right)} T^{\prime}\left(t^{*}\right)+\mathcal{O}\left(T^{\prime 2}\left(t^{*}\right)\right)$.

Because the K-model is nonlinear with respect to temperature variations, the linear diagnostic function is nonlinearly related to these variations. We assume, however, that the second and high order terms $\mathcal{O}\left(T^{\prime 2}\right)$ are negligible. In this case the change of $R$ is related to the temperature variations via the derivative $\partial R\left(\tau_{1}, \tau_{2}\right) / \partial T\left(t^{*}\right)$. This derivative is both a function of the verification interval $\left(\tau_{1}, \tau_{2}\right)$ and the time where the temperature variation is introduced $\left(t=t^{*}\right)$. The value of the derivative for each $t^{*}<\tau_{2}$ would show the actual change of $R$ due to the temperature variation at that time assuming that $T^{\prime}\left(t^{*}\right)=1.0^{\circ}$ and the linear relationship between the temperature forcing and $\mathrm{dCO}_{2} / \mathrm{d} t$ in the model is valid. The derivative $\partial R\left(\tau_{1}, \tau_{2}\right) / \partial T\left(t^{*}\right)$ is, therefore, equivalent to a transfer function between the temperature forcing and the $\mathrm{CO}_{2}$ response in the $\mathrm{K}$-model. As long as the linear assumption is valid, the derivative, when known, can be applied to analyze the response of

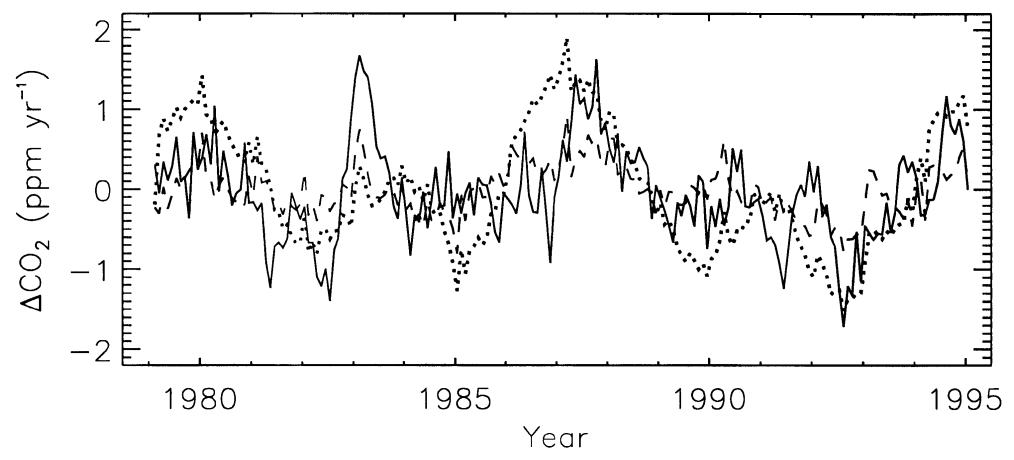

Fig. 3. Time series of observed (solid line) and optimized K-model results for $\mathrm{CO}_{2}$ growth rate. The modeled growth rates shown are from the standard (dotted curve) and no- $N$-feedback (dashed curve) K-model. 
the modeled system without having to integrate the model many times. The linear assumption is always valid for infinitesimally small temperature variations. We tested the validity of this assumption numerically for $T=1.0^{\circ}$ and the agreement between linear and nonlinear responses had $0.1 \%$ or smaller errors.

The derivative $\partial R\left(\tau_{1}, \tau_{2}\right) / \partial T\left(t^{*}\right)$ was computed using the adjoint technique (Vukićević and Hess, 2000; Vukićević and Raeder, 1995; Zou et al, 1993; Hall et al., 1982). First, the linear version of the $\mathrm{K}$-model system of equations was written

$\frac{\mathrm{d} S^{\prime}}{\mathrm{d} t}-K_{\mathrm{S}} S^{\prime}=K_{\mathrm{T}} T^{\prime}$,

where $S^{\prime}$ is the variation of the K-model state vector caused by a variation $T^{\prime}$ in the temperature. $K_{\mathrm{S}}$ is the Jacobian of the rhs of (6) without the linear temperature forcing. $K_{\mathrm{T}}$ is the Jacobian with respect to temperature consisting, therefore, of the linear temperature forcing terms in (6) plus the linearized version of the turnover terms.

Next, a new linear system was defined:

$L \gamma(t)=\frac{\partial g(S(t))}{\partial S(t)}$,

where $g$ is

$g(S(t))=\frac{1}{\tau_{2}-\tau_{1}}\left[S_{1} \delta\left(t-\tau_{2}\right)-S_{1} \delta\left(t-\tau_{1}\right)\right]$,

$\gamma$ is a new vector and $\delta$ is the Dirac delta function and $L$ is a linear operator to be defined from the utility of (13) by deriving an alternative expression to (11) for $\Delta R$. Using (10), (13) and (14) and recognizing that the solution $S_{1}(t)$ depends on the entire K-model solution vector $S$, the linear change of response function $R$ is then written

$\Delta R=\int_{0}^{\tau} \frac{\partial g(S)}{\partial S} S^{\prime}(t) \mathrm{d} t=\int_{0}^{\tau} S^{\prime}(t) L \gamma(t) \mathrm{d} t$.

The interval of integration was extended to $\left(0, \tau>\tau_{2}\right)$ without change of the integral value because of $\delta$ functions in (14). Using the rule for adjoint operations the expression (15) can also be written

$\Delta R=\int_{0}^{\tau} \gamma(t) L^{*} S^{\prime}(t) \mathrm{d} t$,

where $L^{*}$ is the adjoint of $L$ with respect to the time integral in (15). Choosing

$L^{*} S^{\prime} \equiv \frac{\mathrm{d} S^{\prime}}{\mathrm{d} t}-K_{\mathrm{S}} S^{\prime}$

and using the linear K-model eq. (12), the change of $R$ is expressed

$\Delta R=\int_{0}^{\tau} \gamma(t) K_{\mathrm{T}} T^{\prime}(t) \mathrm{d} t$.

The derivative $\partial R\left(\tau_{1}, \tau_{2}\right) / \partial T\left(t^{*}\right)$ in (11) is then given by

$\frac{\partial R\left(\tau_{1}, \tau_{2}\right)}{\partial T\left(t^{*}\right)}=\gamma\left(t^{*}\right) K_{\mathrm{T}}\left(t^{*}\right)$.

Because the adjoint of $L$ in (17) is the homogeneous part of the linearized K-model operator (12), the matrix $L$ is the adjoint of this linear operator. The expression (13), therefore, defines an adjoint system of equations similar to (9a) but the forcing is the gradient $\partial g(S(t)) / \partial S(t)$ instead of the weighted differences between the model solution and observations. The K-model Fortran code and the associated adjoint code are available from http::www.cgd.ucar.edu/VEMAP/Kmodel.

To compute the equivalent of a transfer function between the response $R$ and the temperature variations for all $t^{*}<\tau_{2}$, the adjoint system must be integrated backward in time from $t=\tau_{2}$. As a consequence, the adjoint solution $\gamma\left(t^{*}\right)$ is evaluated at lag times $t=\tau_{2}-t^{*}$.

The equivalent of temperature transfer function for the period 1979-1994 was computed with the $\mathrm{K}$-model adjoint backward time integrations for a sequence of 5-year intervals. Each year contained 12 data points. This produced 117 adjoint solutions, each corresponding to a 5-year period. The model average transfer function was then computed as mean of 117 adjoint solutions. The response function $(R)$ was defined as the 3 month average of $\mathrm{d} S_{1} / \mathrm{d} t$ for each 5-year interval using the last three months in the interval. The model transfer function was computed for both the standard K-model (with the lagged $N$-feedback mechanism) and the no- $N$ feedback $\mathrm{K}$-model. These models were integrated using the corresponding best set of parameters values (Table 1). The best set of parameters was determined from the optimization experiments.

The transfer function between the temperature variations and $\mathrm{dCO}_{2} / \mathrm{d} t$ was also estimated empirically using the temperature and $\mathrm{CO}_{2}$ observa- 
tions. First, the autocorrelations were removed from each time series by subtracting a statistical model fit to these time series (Kendall and Ord, 1990). For this purpose we found a second order auto-regressive model $[\mathrm{AR}(2)]$ to be sufficient, by inspection of the residual auto-correlograms. Then, the "pre-whitened" time series of the temperature and $\mathrm{CO}_{2}$ were used to compute the crosscorrelations. The standard $F$-test was performed on the results to determine significance for each point. The "transfer function" was finally computed from the cross-correlations by multiplying by the ratio of standard deviations of the 2 time series (Kendall and Ord, 1990).

\section{Discussion}

\subsection{Choice of a model}

We based the structure of the K-model on approaches widely used in ecosystem modeling and specifically on the Century ecosystem model (Schimel et al., 1996). We sought to represent those components and processes that we believed would influence year-to-year variations within a 15-year period (1979-1994). We focused on those quickly-responding processes that could be triggered by interannual climate variability rather than processes which might dominate long-term trends such as historical land use or climate change.

Based on suggestions in Braswell et al. (1997) and Schimel et al. (1996), we examined processes linked to the nitrogen cycle that could produce delayed responses (uptake or release of $\mathrm{CO}_{2}$ ) of opposite sign to those triggered during the year of a temperature anomaly. We first considered several variations on the K-model. We implemented the null hypothesis as a K-model with no- $N$ feedback in which delayed effects had to arise from the multicomponent model structure. In the "standard version", $N$ uptake causes a lagged impact on NPP. Finally, we considered a version with the $N$ feedback but no lag, the "no-lag version". The simplest way to distinguish between alternate model formulations is to consider the size of the residual or root mean squared error. We know the residual from the K-model includes: model errors, data errors, anthropogenic flux anomalies and ocean flux anomalies. At this scale, the data errors in $\mathrm{CO}_{2}$ would arise primarily through year-to-year changes in transport. In the extreme, a version of the K-model which fit the observations perfectly would imply zero interannual variability of ocean $\mathrm{CO}_{2}$ exchange. Therefore, we relied only secondarily on differences in goodness of fit between model versions as a criterion for model selection.

We first compared the model variants using forward integrations (Fig. 4), choosing arbitrarily parameters from the mid-points of the ranges shown in Table 1. The no-lag K-model produces amplified variations in $\mathrm{CO}_{2}$ exchange that are poorly phased with, and of greater amplitude than those observed. Additional experimentation suggested that no parameter set produced reasonable simulations with a no-lag $N$-cycle $\mathrm{K}$-model. If the no-lag $N$-cycle were correct, then to match the observed $\mathrm{CO}_{2}$, the ocean or some other process would have to damp out the effects of the biosphere. Even the no-lag biosphere produces relatively small variations in atmospheric $\mathrm{CO}_{2}$ relative to the concentration changes needed to affect ocean uptake or photosynthesis. Changes in one domain (land or oceans) are not mechanistically coupled to the other by atmospheric concentrations in a way that would systematically buffer short-term oscillations. We, therefore rejected from further consideration the no-lag K-model.

We also compared Gaussian lags centered on 1.5 and 2 years in the lagged K-model. Neither of these models have unreasonable variability and both resemble the amplitude and frequency of variations in the data, even without the parameter optimization. Because they substantially resemble each other, we arbitrarily chose the 2 year mean lag version of the model for subsequent analysis. In addition, we also continued to evaluate the "null hypothesis" K-model which lacks an $N$-feedback entirely.

In the next step of analysis, we conducted optimizations of the standard K-model with the 2 year lag and of the no- $N$ feedback K-model (see optimization procedures in Subsection 2.3). We evaluated a number of quantitative and qualitative measures describing the optimization of these two model structures and their appropriateness for representing the observations. First, we considered formal optimization diagnostics. Fig. 5 shows the cost function and the norm of the cost function gradient from the optimizations of both models starting from two different sets of first guesses 

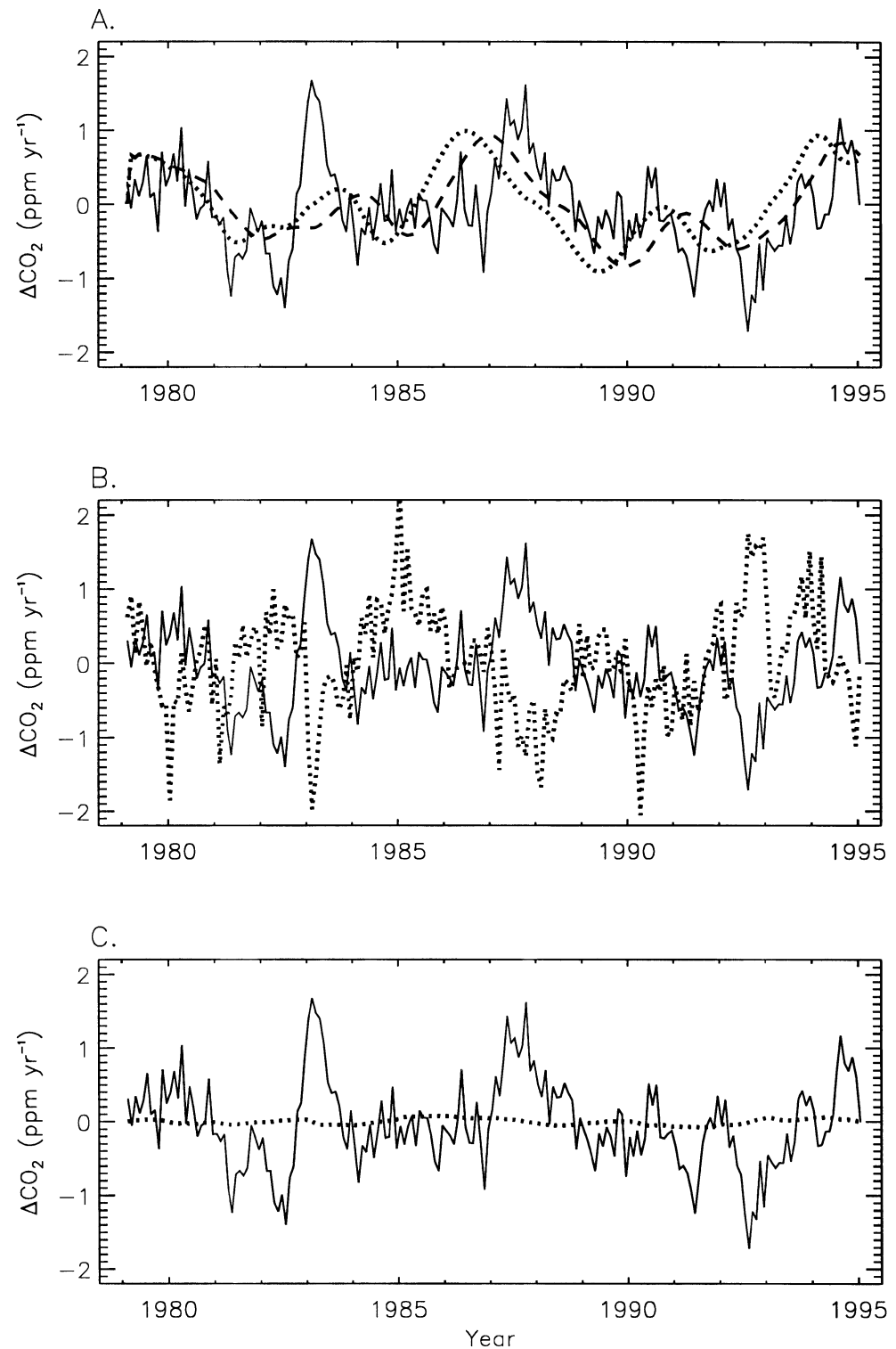

Fig. 4. Comparison of observed $\mathrm{CO}_{2}$ growth rates (solid line) with results of forward simulations of the K-model, using midpoint, "first guess" parameter values (Table 1). (A) Standard case, including explicitly lagged $N$ feedback term. We considered feedback terms with lag centered on 1.5 years (dotted line), and 2 years (dashed line). (B) Input parameters are the same as in (A), but there is no explicit delay in availability of mineralized excess nitrogen $(N$ uptake equals $N$ mineralized for each month). (C) Input parameters are the same as (A) and (B), except that the $N$ feedback term $\mathscr{F}$ (eqs. (4) and (5)), is set to zero. This consequently disables all the $\mathrm{C}: \mathrm{N}$ terms.

(Table 2). The norm of the gradient shows how close the cost function is to a minimum. This norm was used to define the convergence criterion $(\leqslant 0.1)$.
The cost function declined monotonically in all experiments, but the norm of the gradient shows that convergence was achieved formally only for the standard K-model starting from the "rough 


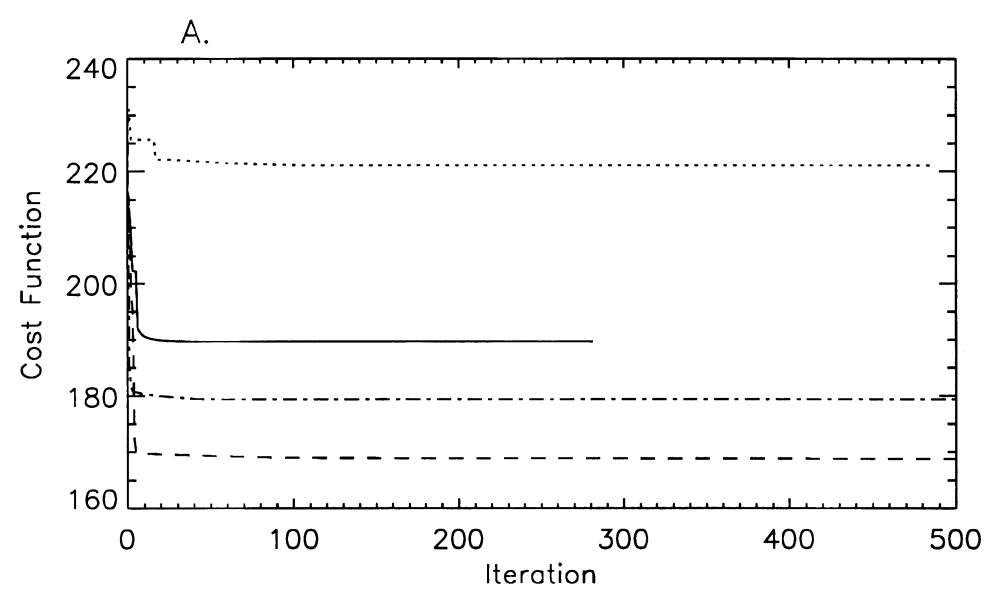

B.

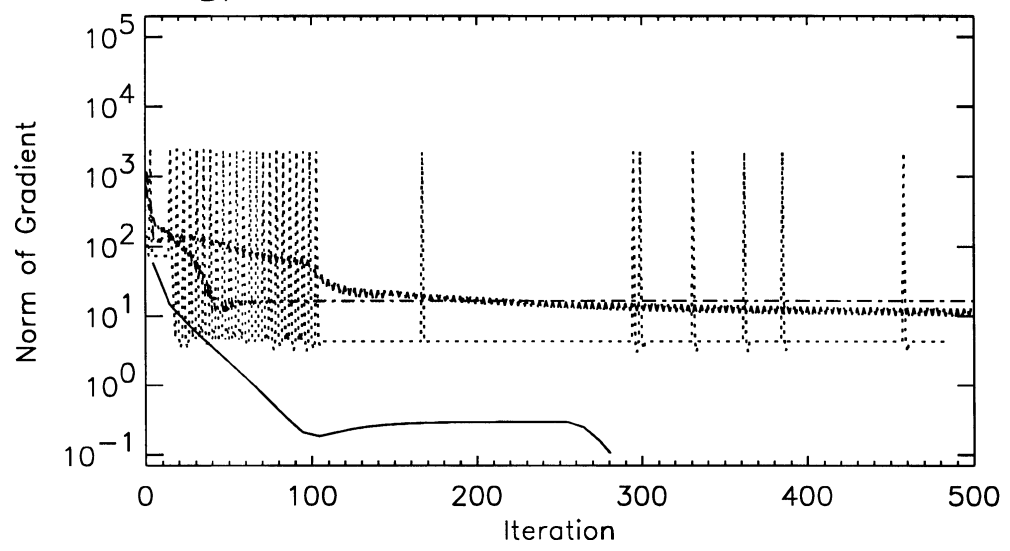

Fig. 5. Convergence of the cost function (A) and the norm of the gradient of the cost function (B). We considered two different models (standard and no- $N$ feedback) and two different first guess parameter sets (midpoint and "rough optimal") resulting in 4 experiments (Table 2): NLAG-O (solid), NONF-O (dashed), NLAG-M (dot-dash) and NONF-M (dotted).

optimal" first guess described in Subsection 2.3. In the no- $N$ feedback experiment with the equivalent first guess the norm declined very slowly for 100 iterations, oscillating as it declined indicating the presence of close multiple minima in the parameter space. The multiple minima are the result of non-quadratic nonlinear relationships between the cost function and the model parameters. The oscillations in the norm of the gradient are even more pronounced in the second experiment using the no- $N$ feedback model (the experiment NONF-M in Table 2). We were not able to find a stable minimum of the cost function for this model. The 2nd experiment for the standard $\mathrm{K}$-model starting from the mid-interval first guess did not converge formally, indicating that the optimization results were sensitive to the first guess. This result is expected in the nonlinear constrained minimizations.

The Hessian matrix condition number is produced as a part of optimization using the Quasi-Newton numerical and is a measure of how well-posed the inverse problem is (for example, see Tarantola, 1987, Chapter 1, for definition of the Hessian matrix and its condition number). The no- $N$ feedback inversion resulted in a very 
large Hessian condition number, suggesting the problem was not well-posed. In qualitative terms, this indicates the difficulty of obtaining a unique parameter set for the given model using the available observations. By inference, the model structure is inappropriate to explain the observed relationships. The Hessian condition number for the standard K-model was small $(\sim 10)$.

Taking into account, the trend in the norm of the gradient (convergence) and the Hessian condition number, we consider the inversion of the standard K-model to have been successful, and inversion of the no- $N$ feedback $\mathrm{K}$-model to have been mathematically unsuccessful. This suggests that the $N$ feedback hypothesis is more consistent with the observations given the gross model structure, and that, conditioned on model structure, the no- $N$ feedback hypothesis is inconsistent with the available global data. Before rejecting the no- $N$ feedback hypothesis, we evaluated the "transfer function" (see Subsection 2.4 for the definition) produced by the standard and no- $N$ feedback model. For this diagnostic and the discussion of the cross-correlations and parameters (below), we used for each model version the best set of parameter values produced in the experiments in Table 2. The best optimization of the parameters in our experiments was produced with the "rough optimal" first guess. Formal convergence was not achieved in the no- $N$ feedback experiments but the new set of parameters at the end of the least unstable optimization experiment (dashed curves in Fig. 5A) gave a better $\mathrm{d} S_{1} / \mathrm{d} t$ solution than the first guess (smaller cost function).

The transfer function of the model is the function that relates an instantaneous change (impulse) in temperature to the derivative of $\mathrm{CO}_{2}$ with time at lags $0-5$ years (Subsection 2.4). A transfer function can also be estimated from the data using regression after the data are "pre-whitened" to remove autocorrelation. This estimate allows us to check whether the sign and time scales of lagged effects (in the $T$ to $\mathrm{dCO}_{2} / \mathrm{d} t$ relationships) in the model are consistent with the data (Fig. 6A).

Fig. 6B shows the transfer function computed for the standard and no- $N$ feedback K-models. The standard model shows a function which is initially positive (warming causes immediate release of $\mathrm{CO}_{2}$ ), has a lagged negative phase, and a subsequent return to positive sign. Note the shape of the lag function appears directly in the transfer function in the form of the lagged Gaussian centered on 2 years. The no- $N$ feedback model shows a similar initial response. As expected, the two models are virtually identical on short time scales, given the Gaussian $N$ lag which shifts most of the $N$-response to longer time scales. The no- $N$ feedback model shows lagged negative response, which however returns monotonically to zero. The overall pattern in observations (Fig. 6A) is more consistent with the standard K-model and less consistent with the no- $N$ lag K-model.

We also computed the cross-correlations of $T$ and $\mathrm{dCO}_{2} / \mathrm{d} t$ from the modeled and observed time series over the period 1979-1994 (Fig. 7). The cross-correlations are less powerful as diagnostics than the transfer functions because they preserve the effects of autocorrelations in the input data (the rough periodicity in temperature anomalies could cause a spurious lagged effect if the actual correlation were instantaneous). But, because the standard K-model produced a cross-correlogram that is different from the no- $N$ feedback model and because the cross-correlation was used in prior work (Braswell et al., 1997), we consider this comparison informative of the relationship between the model and data. The cross correlations for the standard K-model and the data are very similar at short $(<1$ year) and long $(>2.5$ years) lags. They have similar slopes and the same pattern of correlation--anticorrelation unlike the no- $N$ cycle model (dashed curve) which does not produce anticorrelation at long lags. The no- $N$ cycle model cross-correlation curve is, however, more similar to the data at 1-2.5 year lags.

Finally, we examined the parameters from the two model versions. The retrieved values vary somewhat depending upon the first guess in the optimization experiments and upon the smoothing of the data. Despite this, the differences between the standard and no- $N$ cycle K-models are instructive. In the standard model, there is a clear hierarchy in the time scales (turnover times) of the biomass, litter, fast and slow soil pools from less than a year to around 100 years (parameters $k_{2}-k_{5}$ in Table 1). This is similar to our understanding as embodied in models and from isotope data (Schimel et al., 1994; Trumbore et al., 1996). In the no- $N$ cycle $\mathrm{K}$-model, biomass and litter have longer time scales and soil pools shorter time scales than in the standard model. This adjustment 


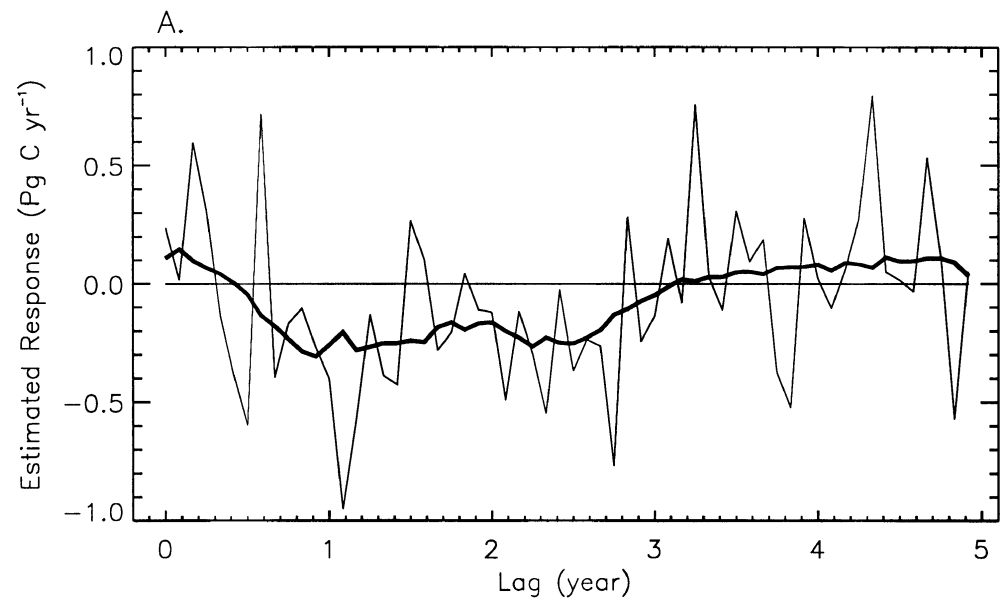

B.

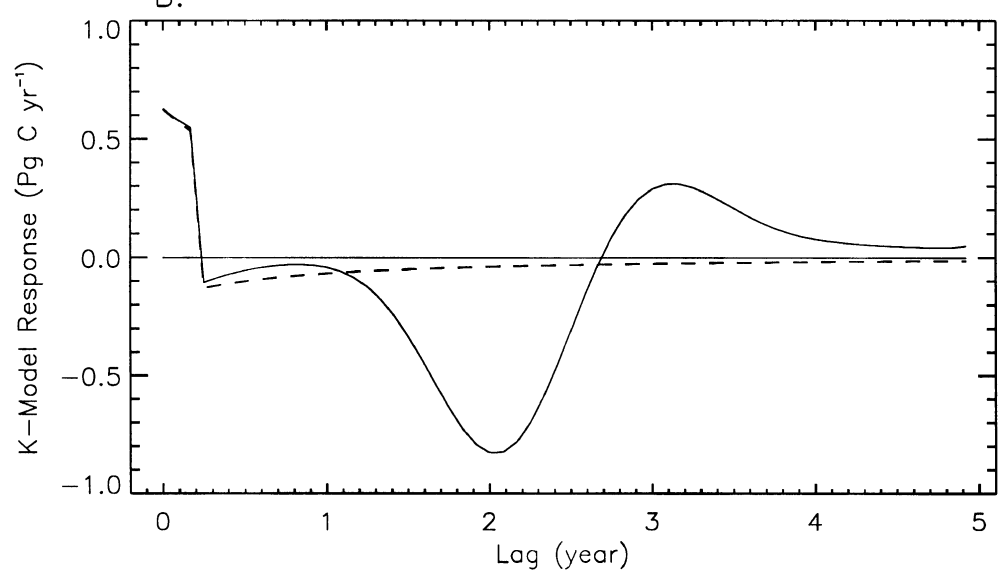

Fig. 6. Temperature impulse transfer functions for global $\mathrm{CO}_{2}$ growth rate. (A) Calculated directly from observations based on the method suggested by Kendall and Ord (1990); the thick line is smoothed for visual purposes only. (B) Calculated using the K-model-adjoint and optimized parameter sets for the standard (solid line) and no- $N$ feedback (dashed line) model version.

is required to attempt to fit the lagged signal in the $T-\mathrm{dCO}_{2} / \mathrm{d} t$ data, with the "slower" soil pools providing some lagged effect. Overall, the change in parameters from the standard to the no- $N$ cycle model is towards a less reasonable parameter set, based on our understanding of carbon biogeochemistry. This again is evidence that the no- $N$ cycle model, driven purely by the biophysical effects of temperature, fits the pattern of multiple time scales evident in the data poorly.

Fig. 8 shows the model's linear sensitivity to its parameters, calculated from its adjoint, for the $N$-cycle and no- $N$ cycle versions. The figure shows the average of instantaneous responses (IR) of $\mathrm{CO}_{2}$ time rate of change resulting from a $1 \%$ positive change in the parameter:

$\mathrm{IR}=\frac{\partial}{\partial \alpha}\left(\frac{\mathrm{dCO}_{2}}{\mathrm{~d} t}\right) \times 0.01 \times \alpha$.

Note that the responses are generally larger in the $N$-cycle model (Fig. 8A). In some cases parameter sensitivities vary depending on the sign of $\mathrm{dCO}_{2} / \mathrm{d} t$. The larger sensitivity in the $N$-cycle model corresponds to the generally larger amplitude in $\mathrm{dCO}_{2} / \mathrm{d} t$ simulated by this version com- 


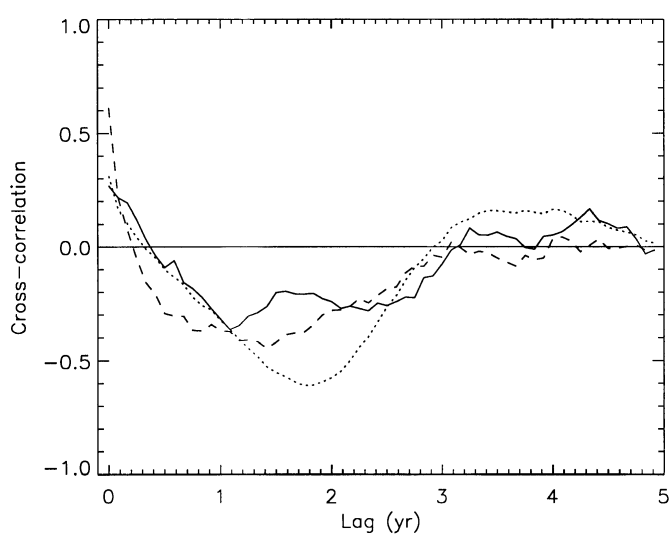

Fig. 7. Lagged cross-correlations. Solid curve shows correlation of observed $\mathrm{CO}_{2}$ anomaly with temperature anomaly for positive lags (temperature leading $\mathrm{CO}_{2}$ ). The remaining curves are for the optimized model with explicitly lagged $N$ feedback (dotted line) and with no$N$-feedback (dashed line).

pared to the no- $N$ cycle version. In both model versions, the sensitivity to $\mathscr{Q}_{r}$ and $\mathscr{Q}_{p}$ is significant. This is reasonable, since the imbalance between these two parameters triggers all of the other model responses (causing carbon accumulation or loss). In the no- $N$ cycle version, the model is sensitive to turnover of "slow" soil organic matter, the parameter $k_{4}$, because this pool contributes much of the lagged effect absent in $N$ cycle. In the $\mathrm{N}$-cycle version of the model, the solution is also sensitive to two crucial $N$ cycle parameters $(\mathscr{F}$ and $\mathrm{cn}_{2}$ in eq. (4)). These two are paired variables, determining by their product the translation of $N$ mineralization into carbon uptake. $\mathscr{F}$ is the fraction of $\mathrm{N}$ utilized in carbon uptake and $\mathrm{Cn}_{2}$, the $\mathrm{C}: \mathrm{N}$ ratio of the new carbon fixed. As $\mathscr{F}$ goes up, so does the amount of carbon fixed for any given $N$ mineralization, and similarly as the $\mathrm{C}: \mathrm{N}$ ratio increases, the amount of $\mathrm{C}$ fixed per unit $N$ captured increases. In a similar stoichiometric sense, the $\mathrm{C}: \mathrm{N}$ ratios of the sensitive litter and slow soil pools determine the $N$ mineralized per unit carbon released during turnover. It has been suggested that not all additional $N$ released during warming can be utilized by plant growth (Houghton et al., 1998). In our analyses, the fraction of $N$ released that is used in plant growth is a free parameter with an estimated value much less than $1.0(\mathscr{F}=0.59)$, though still significant.
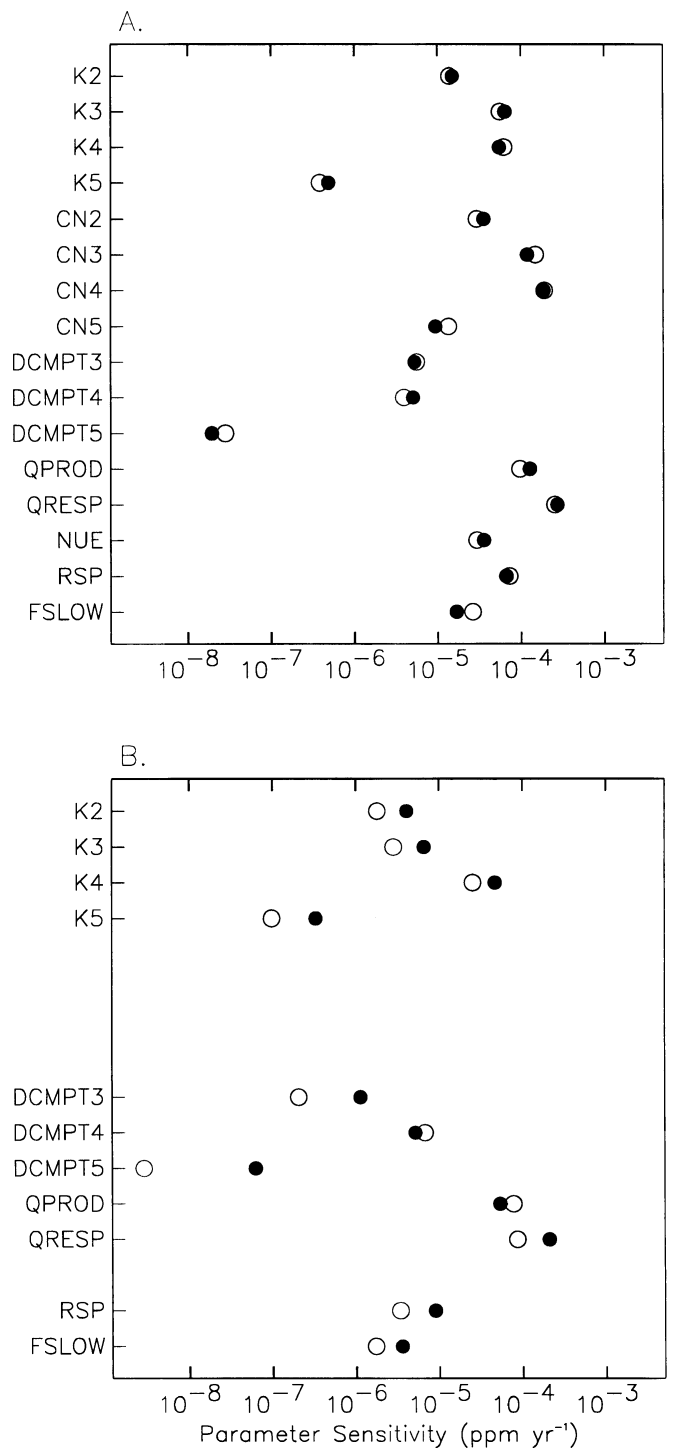

Fig. 8. Average of instantaneous responses of $\mathrm{dCO}_{2} / \mathrm{d} t$ to $1 \%$ positive change in the parameter value. Full circles represent time averages of the positive response $\mathrm{dCO}_{2} / \mathrm{d} t>0$ and open circles represent negative responses $\mathrm{dCO}_{2} / \mathrm{d} t<0$ in the adjoint integration.

\subsection{Climate anomaly patterns and model evaluation}

The structure of the K-model is based on the structure of global ecosystem models, which are implemented grid-cell by grid-cell to capture spatial variations in vegetation, soils and climate. By 
fitting a non-spatial model to global temperature and $\mathrm{CO}_{2}$ growth rates anomalies, we have estimated "bulk" parameters for characteristics. In reality, turnover times, $\mathrm{C}: \mathrm{N}$ ratios and other ecosystem properties vary geographically. The parameter values in the $\mathrm{K}$-model reflect those regions in the biosphere that are affected by temperature anomalies, weighted by the effect of those regions on the atmosphere (that is, weighted by the variability in NEP). Since we don't know a priori those weightings, we estimate the parameters by inversion to best fit the observed temperature-to$\mathrm{CO}_{2} / \mathrm{d} t$ relationships. In the inversion, we only constrained the parameters to lie within the global ranges (tropics to tundra) of analogous parameters in Century, so we made no initial pre-judgment of which biomes might dominate $\mathrm{CO}_{2}$ growth rate anomalies. In this section we discuss how different regions might contribute (or dominate) global responses by examining zonal patterns of temperature anomalies.

Fig. 9 shows zonal variability in temperature two ways. The solid line shows the correlation of temperature anomalies 1979-1994 for each $5^{\circ}$ latitude band with the global mean temperature anomaly time series. From this, it is evident that

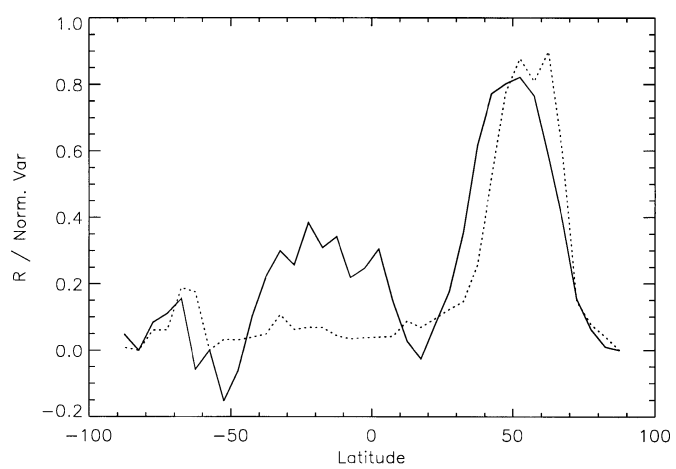

Fig. 9. The latitudinal distribution of the temperature forcing. The correlation between area-weighted temperature anomaly for each $1^{\circ}$ latitude band and the global area-weighted mean (solid line) appears to be greatest in the mid-to-high northern latitudes $(40 \mathrm{~N}-60 \mathrm{~N})$, with a smaller peak in the tropics. A similar pattern can be seen in the area-weighted variance of the $T$ anomaly time series for each latitude band (dotted line). Together, these analyses suggest that the greatest forcing due to interannual temperature variability occurs in the northern temperate zone. Note that while the pattern in the tropics "resembles" the global mean, its overall variability is very low. much of the global variability occurs in the Northern mid-high latitudes, with a secondary contribution from the southern hemisphere tropics. The dashed line indicates the relative variance. The magnitude of interannual temperature variability peaks in the Northern mid-high latitudes and is substantially lower elsewhere. Absolute year-toyear swings of up to $4^{\circ} \mathrm{C}$ occur from $35-40 \mathrm{~N}$ and northwards, while year-to-year changes are typically less than $1^{\circ} \mathrm{C}$ in the tropics. This suggests that temperature-driven interannual variability during the period 1979-1994 was dominated by the effects of the northern hemisphere mid latitude and Southern Boreal ecosystems. This is also the region of the globe in which spatial inverse analyses persistently put the terrestrial sink (Tans et al., 1990; Rayner et al., 1999; Ciais et al., 1997) and where time-dependent inverse analyses suggest significant variability (Ciais et al., 1997; Rayner et al., 1999).

Note the secondary region of correlation in the southern hemisphere tropics (Fig. 9, solid line) which is a region of generally low-amplitude temperature variability and substantially less land area than the mid-latitude northern hemisphere (Fig. 9, dashed line). Other studies, however, have suggested that interannual variability of $\mathrm{CO}_{2}$ fluxes in this region could be high, but mainly driven by precipitation, with droughts causing net $\mathrm{CO}_{2}$ emissions and increased fires leading to $\mathrm{CO}_{2}$ flux to the atmosphere. Tian et al. (1999) suggest net emission to the atmosphere during tropicalsubtropical droughts occurring in El Niño years.

From Fig. 9, we assume that our "bulk" parameters capture effects dominated by temperature forcing and ecosystem response in the northern hemisphere because large, spatial coherent temperature variations affected this region during our study period. Changes to NEP there likely influenced the growth rate of atmospheric $\mathrm{CO}_{2}$ globally. That this region can experience large swings in NEP has been corroborated using entirely independent methods (Ciais et al., 1997; Rayner and Law, 1999). While estimating weighted average or "bulk" parameters over an area of this size (much of the Earth's land area lies between $35-70 \mathrm{~N}$ ) requires that we group together diverse ecosystems, the region is substantially less diverse than the Earth as a whole. Ecosystems with high NPP in this region are generally temperature and nitrogen limited, and so our model structure 
(which includes only temperature and nitrogen effects) can credibly capture a significant portion of interannual variability, though drought and other disturbances which we don't consider, certainly can play a rôle.

\subsection{Implications of the working hypothesis}

Our study supports the idea that the terrestrial ecosystems can contribute to interannual variability in the growth rate of atmospheric $\mathrm{CO}_{2}$. Ecosystem carbon storage is sensitive to climate and, thus, future changes to climate and climate variability should affect ecosystems. Much of the temperature-driven interannual variability of ecosystem carbon exchange may occur in mid-high latitude northern hemisphere ecosystems, the region identified persistently as the location of the bulk of terrestrial carbon uptake. Northern hemisphere uptake may not be very stable from one year to the next, consistent with results by Ciais et al. (1997). This is significant in interpreting "snapshot" or time-averaged spatial inverse calculations (Tans et al., 1990; Fan et al., 1998). The interannual variability of terrestrial uptake is approximately $\pm 2 \mathrm{Gt} C$ per year, an amount equal to the mean global terrestrial sink (Schimel, 1995).

Both $N$-cycle and no- $N$ cycle model versions suggest release of $\mathrm{CO}_{2}$ from terrestrial ecosystems during warm years (and vice versa). The immediate effects of temperature anomalies can be seen in respiration more than in carbon uptake, at least in those ecosystems contributing to $\mathrm{CO}_{2}$ anomalies over the period 1979-1994. Without this asymmetry, the effects of temperature would be zero or reversed (if uptake was more sensitive than respiration). This agrees with understanding of the relationships between temperature, respiration and NPP based on small scale (leaf, plant or soil incubation) experiments. The agreement between analyses based on "scaling up" microscopic parameters (leaf and microbial physiology) with inverse methods from "macroscopic" data lends credibility to the underlying theory. If our analyses are correct, the northern hemisphere terrestrial sink appears to be extremely volatile in magnitude from year to year requiring that we develop a detailed process level understanding if we are to anticipate its likely future magnitude.

While our results are consistent with a body of work arguing that the immediate effects of warming are larger for respiration than photosynthesis, a new line of evidence suggests that warming leads to increased growing season length and enhanced plant growth (Myneni et al., 1997; Randerson et al., 1997). This mechanism can at least locally increase carbon uptake (Goulden et al., 1996). Is this result in conflict with the K-model analysis? First, both $N$-cycle and no- $N$ cycle versions of the $\mathrm{K}$-model suggest an increase in plant growth with warmer conditions. Table 1 shows that in both model versions $\mathscr{Q}_{r}$ (the temperature effect on respiration) is consistently larger than $\mathscr{Q}_{p}$ (the temperature effect on primary productivity). Thus, our analysis suggests a positive effect of warm years on NPP and, by extension, on the amplitude of the seasonal cycle of $\mathrm{CO}_{2}$. In addition, warming can increase simulated carbon storage if the lagged nutrient release mechanism dominates over the direct effects of temperature.

The results of the K-model analysis suggest that, globally, ecosystems behave as if the temperature sensitivity of respiration is larger than that of primary production. If ecosystems show increased NEP in response to larger growing seasons, this would have to be via indirect mechanisms such as nutrient feedbacks. A strong role for nutrients is consistent with experimental studies which suggested that "increased nutrient availability was an important indirect effect of warming" in tundra ecosystems, although increased microbial activity may have been only one of several mechanisms leading to enhanced plant uptake of nutrients (Chapin et al., 1995). Chapin et al. (1995) also found substantial lagged effects of warming on nutrients and also suggested that slow species and litter chemistry shifts with climate could contribute to ecosystem responses on decadal timescales. Species shifts (succession) are unlikely to be a major cause of year-to-year changes in terrestrial NEP but could contribute to decadal trends in carbon uptake at high latitudes (Myneni et al., 1997; Chapin et al., 1995). Current measurements of the atmosphere may not provide sufficient information to allow unambiguous diagnosis of the consequences of temperature on terrestrial carbon storage and must be complemented by regional process and flux studies.

Both our models and the empirical crosscorrelation and transfer function regressions suggest instantaneous and delayed effects of 
temperature on ecosystems. Effects of temperature-mediated ecosystem processes have "memory" of consequences on multiple time scales. The $N$-cycle version of the K-model suggests that this memory may operate via the $N$-cycle and plant nutrient use. Increases in soil respiration are generally accompanied by increase net $N$ mineralization, leading to a coupling between the immediate effects of temperature on respiration and the $N$ cycle. While there has not been extensive specific discussion of delayed effects of temperature, there is supporting evidence. Fertilization of forests typically results in rapid changes to foliar N concentration and delayed effects on NPP (see studies reviewed in Schimel, 1995). Warm temperature anomalies may result in increased available $\mathrm{N}$ too late in the growing season to affect the present years growth but allow perennial plants to stockpile $\mathrm{N}$ for the subsequent year. Many trees determine carbon and nitrogen allocation to foliage based on the previous years' NPP as the bulk of the annual leaf area is formed early in the growing season using stored $\mathrm{C}$ and $\mathrm{N}$ (Waring and Running, 1998). Evidence from a long time series of aboveground NPP data in tallgrass prairie suggests that the relationship between weather and NPP in one year depends upon weather in the previous year (Towne and Owensby, 1988; Seastedt, personal communication). While we represent the lagged effects of $\mathrm{N}$ cycle changes as a simple Gaussian delay, the likely underlying biological mechanisms involve plant allocation of $\mathrm{C}$ and $\mathrm{N}$ to different plant parts (wood, leaves, roots) and phenology, the timing of plant growth relative to the seasonal cycle. Explicit testing of the standard K-model hypothesis should focus on interactions of $\mathrm{N}$ availability with allocation and phenology.

The residual from the K-model (K-modelobservations) shows (Fig. 10B) both positive and negative fluxes. The magnitude of the residuals suggests that significant processes are occurring that are not included in the K-model. The large paired positive and negative residuals in the 1980s are suggestive of a relationship to El Niño (large El Niño events occurred in 1982-83 and 1987). The literature suggests that enhanced ocean uptake should occur during El Niño periods due to "capping" of tropical upwelling by the warm water tongue extending over the Eastern Pacific. Rayner's (Rayner et al., 1999) inverse analysis
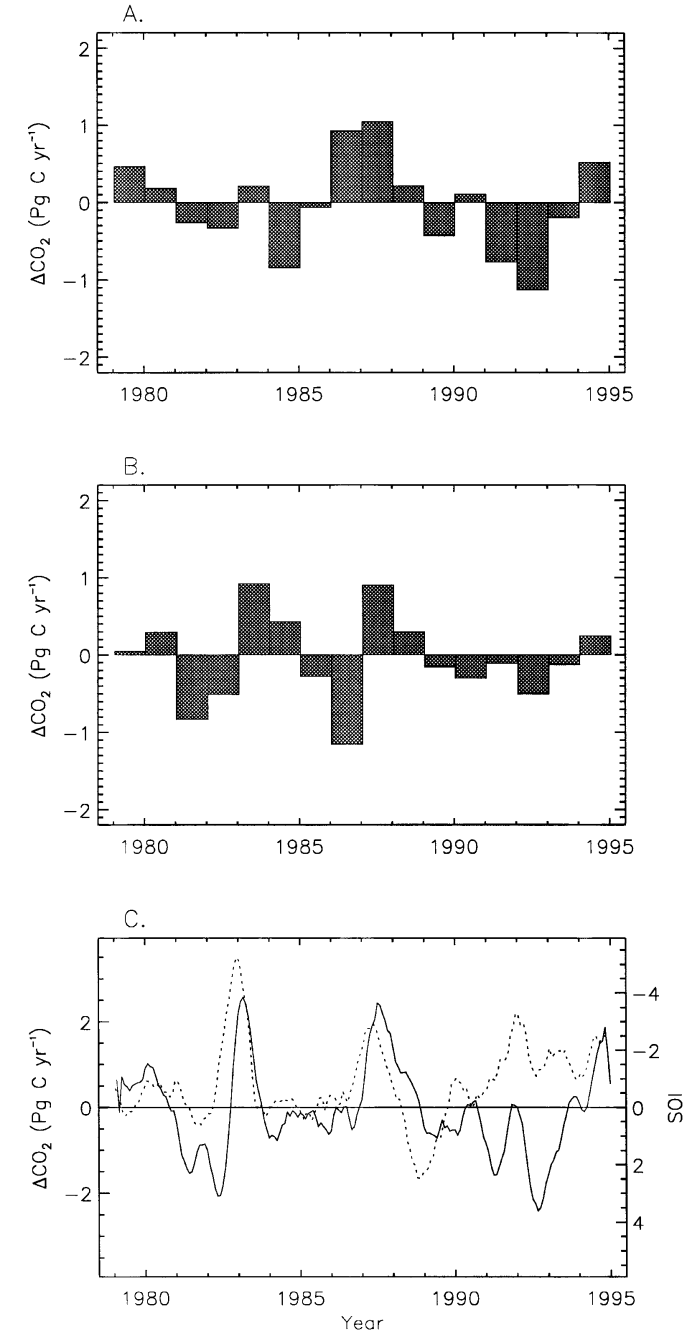

Fig. 10. A: Global C flux produced with the K-model. B: Residual global C fluxes (K-model minus observations) shown as annual averages (grey bars). Positive values indicate an unaccounted source of $\mathrm{CO}_{2}$ to the atmosphere. For comparison, in panel $\mathrm{C}$ are shown the observed $\mathrm{CO}_{2}$ growth rate (solid line), and an index of the El Niño Southern Oscillation (ENSO) cycles (dotted line; data from Trenberth (1984)), both smoothed with a 6-month moving window filter.

suggests anomalous ocean uptake during El Niños. Others have argued for increased terrestrial release in the tropics during El Niño. These losses are due to the droughts that occur in the humid tropics late in El Niño periods and may result from enhanced respiration or from increased bio- 
mass burning (Tian et al., 1999; Nepstad et al., 1999). Since the K-model does not include precipitation effects or biomass buring, any signal from these processes would appear in the residual (unless highly correlated with temperature anomalies). The residuals from the K-model should not be over-interpreted but the residual fluxes (Fig. 10B) show signals that consistent with anomalous ocean and land exchange during El Niño periods. New tools and observations must be brought to bear to test whether land or ocean processes dominate to produce anomalous fluxes. Atmospheric oxygen, isotopes in $\mathrm{CO}_{2}$, new remote sensing techniques and process modeling can all contribute to resolving this question.

Note also the lack of clear residual signals during the prolonged weak El Niño of the 1990s (Figs. 10A, C), a period that also contains the cooling associated with the Mt. Pinatubo eruption. Either the effects of El Niño may have been masked by the Pinatubo effect, or, for an unknown reason, the behavior of the carbon system was different in the 1990s.

Terrestrial ecosystems could also contribute to residual fluxes through processes that are not included in the K-model. Recent work in Brazil (Tian et al., 1998; Nepstad et al., 1999) suggests high emissions from tropical forests during El Niño. Tian et al. (1999) using the process model TEM calculate anomalously high respiration fluxes late in El Niño due to drought (the water balance is not included in the K-model). Nepstad et al. (1999) suggest higher-than-normal biomass burning fluxes during El Niño, resulting from deforestation and other human activities.

\section{Conclusions}

We conclude, first, that the atmospheric record shows a significant relationship between temperature and $\mathrm{CO}_{2}$ fluxes likely due to terrestrial ecosystem responses. Second, the macroscopic behavior of the carbon system suggests that, as hypothesized from small-scale experiments, the temperature dependence of respiration is larger than that of NPP, leading to negative NEP during warm periods. Third, the effects of temperature on ecosystems are manifest as both indirect, lagged ecosystem responses and by direct physiological effects. The lagged effects suggest a role for soil nitrogen cycling and plant nitrogen metabolism in the global carbon cycle as well as direct plant and microbial physiological response to temperature. The residuals from the model (modelobservations) demonstrate that there are significant interannual dynamics in $\mathrm{CO}_{2}$ that are not directly related to temperature. These could be linked to both tropical oceanic and ecosystem responses to the El Niño. Warming and longer growing seasons at high latitudes should cause increased NPP but could either increase or decrease NEP, depending on whether the direct physiological or indirect ecosystem effects of temperature dominated. Long-term experimental studies should be able to distinguish which processes dominate carbon fluxes.

\section{Acknowledgments}

T. Vukićević was supported initially at NCAR (NCAR is sponsored by the National Science Foundation). Vukićević was partially supported by NASA IDS Grant NAGW-2662, while at NCAR. Vukićević is currently affiliated with the Cooperative Institute for Research in the Atmosphere and is supported by DOD Grant DAAL01-98-2-0078. B. Braswell was initially supported by NASA IDS Grant NAGW-2662. Braswell is currently affiliated with the MaxPlanck-Institut für Biogeochimie. During this study D. Schimel was supported by NASA IDS Grant NAGW-2662, NCAR and the Max-PlanckInstitut für Biogeochimie. The three authors contributed equally to realizing this project. We thank E. Linder for suggesting the empirical transfer function analysis technique. We also thank S. Doney and D. Nychka for helpful comments on an earlier version of this manuscript. 


\section{REFERENCES}

Bennett A. F. and McIntosh, P. C. 1982. Open ocean modeling as an inverse problem: tidal theory. J. Phys. Oceanog. 12, 1004-1018.

Braswell, B. H., Schimel, D. S., Linder, E. and Moore, B. 1997. The response of global terrestrial ecosystems to interannual temperature variability. Science $\mathbf{2 3 8}$ $870-872$.

Cao, M. and Woodward, F. I. 1998. Dynamic responses of terrestrial ecosystem carbon cycling to global climate change. Nature 393, 249-252.

Chapin, F. S., Shaver, G. R., Giblin, A. E., Nadelhoffer, K. J. and Laundre, J. A. 1995. Responses of arctic tundra to experimental and observed changes in climate. Ecology 76, 694-711.

Ciais, P., Tans, P. P., Trolier, M., White, M. and Francey, R. J. 1995. A large Northern Hemisphere terrestrial $\mathrm{CO}_{2}$ sink indicated by the $13 \mathrm{C} / 12 \mathrm{C}$ ratio of atmospheric $\mathrm{CO}_{2}$. Science 269, 1098-1102.

Ciais, P., Tans. P. P., Denning, A. S. Francey, R. J., Trolier, M., Meijer, H. A. J., White, J. W. C., Berry, J. A., Randall, D. A., Collatz, G. J., Sellers, P. J., Monfray, P. and Heimann, M. 1997. A three-dimensional synthesis study of delta $18 \mathrm{O}$ in atmospheric $\mathrm{CO}_{2}$, 1: Surface fluxes. J. Geophys. Res. 102 5857-5872.

Daley, R. 1991. Atmospheric data analysis. Cambridge Atmospheric and Space Science Series (J. T. Houghton, M. J. Rycroft and A. J. Dessler, eds.). Cambridge University Press, Cambridge. 457 pp.

Enting I. G. and Mansbridge, J. V. 1991. Latitudinal distribution of sources and sinks of $\mathrm{CO}_{2}$ : results of an inversion study. Tellus 43B, 156-170.

Fan, S., Gloor, M., Mahlman, J., Pacala, S., Sarmiento, J., Takahashi, T. and Tans, P. P. 1998. A large terrestrial carbon sink in North America implied by atmospheric and oceanic $\mathrm{CO}_{2}$ data and models. Science 282, 442-446.

Gillette, D. A., Komhyr, W. D., Waterman, L. S., Steele, L. P. and Gammon, R. H. 1987. The NOAA/GMCC continuous $\mathrm{CO}_{2}$ record at the South Pole, 1975-1982. J. Geophys. Res. 92, 4231-4240.

Goulden, M. L., Munger, J. W., Fan, S.-M., Daube, B. C and Wofsy, S. C. 1996. Science 271, 1576-1578.

Hall, M. C. G., Caccuci, D. G. and Schlesinger, M. E. 1982. Sensitivity analysis of a radiative convective model by the adjoint method. J. Atmos. Sci. 39 , 2083-2050.

Holland, E. A., Townsend, A. R. and Vitousek, P. M. 1995. Variability in temperature regulation of $\mathrm{CO}_{2}$ fluxes and $\mathrm{N}$ mineralization from five Hawaiian soils implications for a changing climate. Global Change Biology 1, 115-123.

Houghton, R. A., Davidson, E. A. and Woodwell, G. M 1998. Missing sinks, feedbacks, and understanding the role of terrestrial ecosystems in the global carbon balance. Global Biogeochem. Cycles 12, 25-34.
Jones, P. D. 1994. Hemispheric surface air temperature variations: a reanalysis and an update to 1993. J. Climate 7, 1794-1802.

Keeling, C. D., Whorf, T. P., Wahlen, M. and van der Plicht, J. 1995. Interannual extremes in the rate of rise of atmospheric carbon dioxide since 1980. Nature 375, 666-670.

Kendall, M. and Ord. J. K. 1990. Time series. Edward Arnold Publishing, 3rd edition. Kent, UK. 296 pp.

Myneni, R. B., Keeling, C. D., Tucker, C. J., Asrar, G. and Nemani, R. R. 1997. Increased plant growth in the northern high latitudes from 1981 to 1991 . Nature 386, 698-702.

Nepstad, D. C., Verissimo, Alencar, A., Nobre, C., Lima, E., Lefebvre, P., Schlesinger, P., Potter, C., Moutinho, P., Mendoza, E., Cochrane, M. and Brooks, V. 1999. Large scale impoverishment of Amazonian forests by logging and fire. Nature 398 , 505-508.

Parker, D. E., Jones, P. D., Bevan, A. and Folland, C. K 1994. Interdecadal changes of surface temperature since the late 19th century. J. Geophys. Res. 99, 14,373-14,399.

Parton, W. J., Schimel, D. S. and Cole, C. V. 1987. Dynamics of $\mathrm{C}, \mathrm{N}, \mathrm{S}$, and $\mathrm{P}$ in grassland soils: A model. Biogeochemistry 5a, 109-131.

Parton, W. J., Scurlock, J. M. O., Ojima, D. S., Gilmanov, T. G., Scholes, R. J., Schimel, D. S., Kirchner, T., Menaut, J.-C., Seastedt, T.,Garcia Moya, E., Kamnalrut, A. and Kinyamario, J. I. 1993. Observations and modeling of biomass and soil organic matter dynamics for the grassland biome worldwide. Global Biogeochemical Cycles 7a, 785-809.

Press, W. H., Teukolsky, S. A., Vetterling, W. T. and Flannery, B. P. 1992. Numerical Recipes in C: The art of scientific computing, 2nd edition. Cambridge University Press.

Randerson, J. T., Thompson, M. V., Conway, T. J., Fung, I. Y. and Field, C. B. 1997. The contribution of terrestrial sources and sinks to trends in the seasonal cycle of atmospheric carbon dioxide. Global Biogeochemical Cycles 11, 535-560.

Rayner, P. J. and Law, R. M. 1999. The interannual variability of the global carbon cycle. Tellus 51B, 210-212.

Rayner, P. J., Law, R. M. and Dargaville, R. 1999. The relationship between tropical $\mathrm{CO}_{2}$ fluxes and the El Niño-Southern Oscillation. Geophysical Research Letters 26, 493-496.

Schimel, D. S. 1995. Terrestrial ecosystems and the carbon cycle. Global Change Biology 1, 77-91.

Schimel, D. S., Braswell, B. H., Holland, E. A., McKeown, R., Ojima, D. S., Painter, T. H., Parton, W. J. and Townsend, A. R. 1994. Climatic, edaphic, and biotic controls over storage and turnover of 
carbon in soils. Global Biogeochemical Cycles 8, 279-293.

Schimel, D. S., Braswell, B. H., McKeown, R., Ojima, D. S., Parton, W. J. and Pulliam, W. 1996. Climate and nitrogen controls on the geography and time scales of terrestrial biogeochemical cycling. Global Biogeochemical Cycles 10, 677-692.

Schimel, D. S., VEMAP Participants, and Braswell, B. H. 1997. Continental scale variability in ecosystem processes: models, data, and the role of disturbance. Ecological Monographs 67, 251-271.

Smedstad O. M. and O'Brien, J. J. 1991. Variational data assimilation and parameter estimation in an equatorial Pacific Ocean model. Progr. Oceanog. 26, 179-241.

Tarantola, A. 1987. Inverse Problem Theory. Elsevier Science B. V., 613 pp.

Tans, P. P., Fung, I. Y. and Takahashi, T. 1990. Observational constraints on the global atmospheric $\mathrm{CO}_{2}$ budget. Science 247, 1431-1438.

Thoning, K. W., Tans, P. P., and Komhyr, W. D. 1989. Atmospheric carbon dioxide at Mauna Loa Observatory, 2. Analysis of the NOAA/GMCC data, 1974-1985. J. Geophys. Res. 94, 8549-8565.

Tian, H., Melillo, J. M., Kicklighter, D. W., McGuire, A. D., Helfrich, J. V. K., Moore, B. and Vorosmarty,
C. J. 1998. Effect of interannual climate variability on carbon storage in Amazonian ecosystems. Nature 396, 664-667.

Trenberth, K. 1984. Signal versus noise in the Southern Oscillation. Mon. Wea. Rev. 112, 326-332.

Trumbore, S. E., Chadwick, O. A. and Amundson, R. 1996. Rapid exchange between soil carbon and atmospheric carbon dioxide driven by temperature change. Science 272, 393-405.

Vukićević, T. and Raeder, K. 1995. Use of an adjoint model for finding triggers for Alpine lee cyclogenesis. Mon. Wea. Rev. 123, 800-816.

Vukićevuć, T. and Hess, P. 2000. Analysis of tropospheric transport during MLOPEX using adjoint technique. Geophys. Res. 105, 7213-7230.

Waring, R. H. and Running, S. W. 1998. Forest ecosystems: analysis at multiple scales. San Diego Academic Press, $231 \mathrm{pp}$.

Zou, X., Navon, I. M. and Le Dimet, F. X. 1992. An optimal nudging data assimilation scheme using parameter estimation. Q. J. R. Met. Soc. 118, 1163-1186.

Zou, X., Barcilon, A., Navon, I. M., Whitaker, J. and Caccuci, D. G. 1993. An adjoint sensitivity study of blocking in a two-layer isentropic model. Mon. Wea. Rev. 121, 2833-2857. 